\title{
Parental Stress and Parent-Child Relationships in Recently Divorced, Custodial Mothers
}

\author{
Kelly L. Murphy, PhD \\ Magy Martin, EdD \\ Walden University, USA \\ Don Martin, PhD
}

Youngstown State University, USA

Doi: 10.19044/ejes.v5no2a1 URL:http://dx.doi.org/10.19044/ejes.v5no2a1

\begin{abstract}
Divorce often creates significant stress that can have an impact on parent-child relationship satisfaction. The purpose of this study was to examine the predictive relationship between parental stress as measured by the Parenting Stress Index, $4^{\text {th }}$ Edition, Short Form (PSI-4-SF) and the parentchild relationship satisfaction as measured by the Parent-Child Relationship Inventory (PCRI) following a separation or divorce. A sample of 17 recently separated or divorced, custodial mothers who had at least one child between the ages 5-13 years were recruited through local schools. Participants completed the PSI-4-SF, the PCRI, and a demographics questionnaire online. A correlation and regression analysis were conducted to analyze the relationship between parental stress and the level of parent-child relationship satisfaction, which was found to possess a significant negative relationship. The stress of the mother was found to affect the parent-child relationship. Neither child gender or child age influenced the relationship between parental stress and parent-child relationship satisfaction. However, mother's with sons reported higher parental satisfaction than mothers with daughters.
\end{abstract}

Keywords: Children of divorce and family, parent stress and divorce, child custody.

\section{Introduction}

Divorce is one of the most stressful life-changing events an individual may experience (Lamela \& Figueiredo, 2011). Recent U.S. census data has indicated that close to 2 million adults go through divorce each year (Center for Disease Control, 2015). Seventeen percent of marriages end before the fifth anniversary, and an additional $28 \%$ end before their 15th anniversary, which means that children also may be affected by divorce (Kreider \& Ellis, 2011). 
The first year following a separation or divorce is the most difficult; thus, making quick, decisive actions are critical to the well-being of the children (Cohen \& Finzi-Dottan, 2005). The divorce process typically disrupts a child's daily routine, which can cause stress and have a long-term effect on the child's attachment to his or her parents (Sutherland, Altenhofen, \& Biringen, 2012). Parental divorce can drastically alter the parent-child relationship, and in the long-term can impact the child who lived through it (Wallerstein, Lewis, \& Rosenthal, 2013). Divorce also has an impact on the divorcing adults by completely changing their lives and daily routines which can be extremely stressful. One or both parents may need to find a new house or apartment. If one adult has been a stay-at-home caregiver, he or she might need to return to work to pay bills (Sutherland et al., 2012). With financial strain, increased stress, and tension between adults many children experience emotional, physical and mental health consequences that may go unnoticed by otherwise distracted parents (Wallerstein \& Lewis, 2004). Kahl et al., (2007) reported that this overall stress felt by adults going through a divorce and the stress felt by the children is problematic in many ways, disrupting many areas of children's lives, including social, economic, and academic.

The stress from a possible divorce can begin months or even years before the physical separation takes place as the relationship deteriorates to the point of deciding to separate. Kristjansson, Sigfusdottir, Allegrante, and Helgason (2009) surmised that the stress level of a family contemplating divorce could be quite high. Cooperation between parents at the time of separation or divorce can reduce the stress felt by the household, which can help to protect the parent-child attachment style. Stress associated with divorce influences all family members and adds strains on the relations among family members, often leading to additional family conflicts (Afifi, Huber \& Ohs, 2006; Breivik \& Olweus, 2006). When parents are separating, they may be distracted and become emotionally and physically unavailable to their children (Sutherland et al., 2012). It was reported by Taylor et al. (2011) that in times of trauma, some individuals become egocentric and fail to think of the needs of their children which also can add stress to the household. A divorce can be just one indicator of more underlying familial problems that need to be addressed (Huurre, Junkkari, \& Aro, 2006).

A parent-child relationship is going to be more stable when there are support and love within the relationship (Wallerstein, et al., 2013). Most custody agreements leave the children in the mother's care for a significant time. To improve mother-child relationships, some topics of conversation could include discussing good things about the father, the mother's happiness, hobbies, and the mother's hope for the future. Topics that can worsen the mother-child relationship include discussing negative aspects of the father, other men, and mom dating, mother's sexual desires, financial worries, job 
problems, or child support (Luedemann, Ehrenberg, \& Hunter, 2006). Regardless of the family dynamics, the mother-daughter relationship has a higher emotional closeness compared with mother-son relationships (Beelmann \& Schmidt-Denter, 2009). While having a great relationship with both parents is ideal, this is rarely the case following parental divorce. It is never appropriate to put the children in the middle of financial concerns and conflicts that are not age appropriate. Children may typically connect financial support to emotional involvement that could significantly affect their relationship with the noncustodial parent (Eldar-Avidan, Haj-Yahia, \& Greenbaum, 2008).

Following a divorce, more than 50\% of mothers become less responsive and less available to kids (Beelmann \& Schmidt-Denter, 2009). Mothers have the challenging task of attempting to separate their feelings about the failed marriage and parenting practices. Wallerstein et al. (2013) stresses how crucial it is for mothers to remain 'good moms,' if they fail to do this, the children are more likely to be lonely, angry, and confused. The mother-child relationship typically has a profound influence on the fatherchild relationship. When the father distances himself or disappears from the child's life, the mother has the difficult job of helping the child work through this rejection (Kenyon \& Koerner, 2008; Koerner,Kenyon \& Rankin, 2006; Wallerstein et al., 2013). However, with increased conflicts, Harkvoort, Bos, Val Balen, and Hermanns (2012) and Lansford, et al. (2006) found that, when the children experienced much conflict with their mother, they also had high reports of conflict with their father. This also was found to be similar to positive relationships as well. When children reported higher feelings of being accepted by their mother, they also tended to report higher feelings of being accepted by their father.

\section{Main Text}

The purpose of this quantitative study was to determine if the parent's stress level predicted parent-child relationship satisfaction as reported by the mothers. In this study, child gender and child age were also exampled to examine if either of these characteristics influenced the strength or direction of the relationship between parental stress and the reported satisfaction of the parent-child relationship. To attempt to ensure there were no other demographic characteristics that had influenced either parental stress or the parent-child relationship satisfaction, personal characteristics, such as the mother's age, mother's education, and the ethnicity of both mother and child, the separation status of the parents, and the amount of father involvement were examined. The characteristics that exhibited an influence on either variable were first entered as control variables.

A total of 17 participants for inclusion included: 1) being a mother to 
a child between the ages $5-13 ; 2$ ) being separated or divorced from the father within the past 24 months; 3 ) have at minimum shared custody (living with the child at least $50 \%$ of the time); and 4) cannot be in a serious romantic relationship or have a new romantic partner living with the child. If the mother had more than one child in the 5-13-year-old age range, she was instructed to choose one child to think of while completing the PSI-4-SF and the PCRI and indicate this child's age and gender on the demographics questionnaire where indicated. Of the 17 responses that did meet the study inclusion criteria, descriptive statistics were examined for the nominal and continuous level variables. The gender of children was distributed between 10 males and 7 females. Most of the participants were 36-40 years old $(n=6,35.3 \%)$. The largest proportion of the participants had obtained their Bachelor's degree $(n$ $=7,41.2 \%)$. Most of the participants had only one child $(n=8,47.1 \%)$. Children's ages ranged from 5 years to 13 years, with an average age of 9.12 years $(S D=2.57)$. Household income ranged from $\$ 20,000.00$ to $\$ 140,000.00$, with an average of $\$ 58,875.00(S D=\$ 32,626.93)$. The descriptive statistics of the respondents' demographic characteristics are presented in Table 1.

Table 1: Descriptive Statistics of Demographical Data

\begin{tabular}{lll}
\hline Demographic & $n$ & $\%$ \\
\hline Gender of child & & \\
Male & 10 & 58.8 \\
Female & 7 & 41.2 \\
Age of parent & 2 & 11.8 \\
$26-30$ & 3 & 17.6 \\
$31-35$ & 6 & 35.3 \\
$36-40$ & 1 & 5.9 \\
$41-45$ & 5 & 29.4 \\
$46-50$ & & \\
Highest level of education & 1 & 5.9 \\
High school degree or equivalent & 3 & 17.6 \\
Some college but not degree & 2 & 11.8 \\
Associate degree & 7 & 41.2 \\
Bachelor degree & 4 & 23.5 \\
Graduate degree & & \\
Number of children & 8 & 47.1 \\
1 & 3 & 17.6 \\
2 & 5 & 29.4 \\
3 & 1 & 5.9 \\
4
\end{tabular}

Note. Due to rounding error, percentages may not always sum to $100 \%$.

\section{Descriptive Statistics of Continuous Variables}

Parental stress scores ranged from 53 to 137, with an average of 83.24 $(S D=21.24)$. Parent-child relationship satisfaction scores were based on the 
Communication subscale of the PCRI and ranged from 25 to 50, with an average of $39.76(S D=8.12)$. Descriptive statistics for the continuous variables of interest are presented in Table 2.

Table 2:Mean, Standard Deviation, Range, Skewness, and Kurtosis for Continuous Variables $(N=17)$

\begin{tabular}{lllllll}
\hline Continuous Variables & Min & Max & $M$ & SD & Skewness & Kurtosis \\
\hline & & & & & & \\
Parental stress & 53.00 & 137.00 & 83.24 & 21.24 & 0.92 & 1.07 \\
$\begin{array}{l}\text { Parent-child } \\
\text { relationship }\end{array}$ & 25.00 & 50.00 & 39.76 & 8.12 & -0.41 & -1.23 \\
satisfaction & & & & & & \\
\hline
\end{tabular}

The PSI-4-SF, created by Richard Abidin (2012), was utilized to help measure the amount stress the parent has in her life that pertains to the child, herself and overall life stressors. The PCRI created by A. Gerard (1994) was utilized to measure the parent's feelings or attitudes about being a parent to his or her children. The demographic questionnaire included necessary information about the mother: their age, separation status (separated, legally separated, divorced), education level (less than high school degree, high school degree or equivalent, some college, but no degree, bachelor's degree, or graduate degree), and ethnicity (American Indian or Alaskan Native, Asian or Pacific Islander, Black or African American, Hispanic or Latino, White/Caucasian, or other). Along with separation status, participants were asked how much time has passed since the separation or divorce. Custody arrangement details were also asked. Mothers selected the most appropriate way to describe their current custody arrangement: full custody, shared or joint custody, or if the father has no contact. Mothers estimated the time percentage of where the child spends their time (70\% with the mother and 30\% with the father for example). Questions about children that the mother answered included ethnicity (American Indian or Alaskan Native, Asian or Pacific Islander, Black or African American, Hispanic or Latino, White/Caucasian, or other), the number of children in the household, and age and gender of each child. Because they were asked to think of only one child when completing the PSI-4-SF and the PCRI, participants were asked to indicate the age and gender of the child in mind when completing the surveys.

This study was conducted entirely on the online survey site, SurveyMonkey. Participants were recruited via advertising in the local school district's electronic newsletter and on the district's Facebook page. The study ran for approximately for six weeks. Data for this study were collected by working with a local school district to put an advertisement in their electronic newsletter. The data was collected from a total of 22 respondents. Once the data collection process was complete, the raw data were inputted into SPSS version 24.0 for Windows. Two participants did not complete major sections 
of the questionnaire and were subsequently removed. Three of the participants did not meet the inclusion criteria for children's ages and time since the divorce. The final sample size consisted of 17 participants.

Spearman bivariate correlations were computed to determine if there were any significant relationships between the demographic and study variables. Parent age was significantly positively correlated with child's age $(r=.62, p=.009)$. No other correlations were significant. Therefore, parent age was included as a covariate in the main analyses. The correlation coefficients are presented in Table 3.

Table 3:Correlations Between Demographic and Study Variables

\begin{tabular}{lllll}
\hline Demographic Variable & Child's age & Child gender & Parental stress & Parent-child relationship satisfaction \\
\hline & & & & \\
Parent age & $.62^{*}$ & -.24 & .09 & -.26 \\
Number of children & .48 & -.05 & .32 & -.17 \\
Education & .00 & -.12 & -.32 & .12 \\
Household income & -.21 & -.32 & -.04 & -.23 \\
\hline
\end{tabular}

Note. ${ }^{*} p<.05$. Spearman correlations reported for ordinal variables (parent age and education).

Research Question 1: Is the stress level of recently separated or divorced custodial mothers associated with the reported parent-child relationship satisfaction?

The first analysis examined the relationship between parental stress and the parent-child relationship satisfaction using the scores from the PSI-4$\mathrm{SF}$ and the PCRI. A Pearson correlation and a hierarchical linear regression were conducted to examine the relationship between parental stress and the quality of the parent-child relationship. Cohen's standard (Cohen, 1988) was used to interpret the strength of the correlation coefficients, where coefficients between .10 and .29 represented a small association; coefficients between .30 and .49 represent a medium association, and coefficients above .50 represent a significant association.

Results of the Pearson correlation indicated that there was a statistically significant negative relationship between parental stress and parent-child relationship satisfaction $(r=-.76, p<.001)$. By using Cohen's standard, the relationship between the variables represented a strong negative association. Therefore, the participants with higher parental stress scores tended to have lower scores for parent-child relationship satisfaction.

A hierarchical linear regression was conducted to examine the predictive relationship between parental stress and parent-child relationship satisfaction while controlling for the parents age. Using the hierarchical linear regression method, the control variables were entered as the first step of the model. In the second step, the predictor (parental stress) was inputted. The change in $R^{2}$ between the two steps was noted. 
Results of the first step of the regression model indicated that the demographic control variable did not have an effect on parent-child relationship satisfaction, $\left(F(1,15)=0.90, p=.358, R^{2}=.057\right)$. The $R^{2}$ value indicates that approximately $5.7 \%$ of the variance in parent-child relationship satisfaction scores can be explained by the control variable. The parents age was not a significant predictor in the model.

Results of the second step of the regression model indicated that the demographic variable and parental stress have a significant collective effect on parent-child relationship satisfaction, $\left(F(2,14)=9.92, p=.002, R^{2}=.586\right)$. The $R^{2}$ value indicates that approximately $58.6 \%$ of the variance in parentchild relationship satisfaction scores can be explained by the control variables and the inclusion of parental stress in the model. An additional 52.9\% of the variance could be explained by the inclusion of parental stress in the model beyond what is accounted for by the demographic factors alone. Parental stress $(B=-0.29, t=-4.23, p=.001)$ was a significant predictor in the model, such that with every one-unit increase in parental stress, parental-child relationship satisfaction decreased by 0.29 units. The null hypothesis $\left(H_{0} l\right)$ for research question one could be rejected The results for the hierarchical linear regression are presented in Table 4.

Table 4: Results for Regression with Parental Stress Predicting Parent-Child Relationship Satisfaction, While Controlling for Demographics

\begin{tabular}{lcccccc}
\hline Source & $B$ & $S E$ & $\beta$ & $t$ & $p$ & $V I F$ \\
\hline Step 1 & & & & & & \\
Parent age & -1.39 & 1.46 & -0.24 & -0.95 & .358 & 1.00 \\
Step 2 & & & & & & \\
Parent age & -0.46 & 1.03 & -0.08 & -0.45 & .661 & 1.05 \\
Parental stress & -0.29 & 0.07 & -0.75 & -4.23 & .001 & 1.05 \\
\hline
\end{tabular}

Note. Step One: $F(1,15)=0.90, p=.358, R^{2}=.057$

Step Two: $F(2,14)=9.92, p=.002, R^{2}=.586$

Research Question 2: Does the child's gender moderate the relationship between parental stress and the reported parent-child relationship satisfaction?

The second analysis examined the moderating effect that the child's gender had on the relationship between parental stress and parent-child relationship satisfaction using the scores from the PSI-4-SF and the PCRI. A hierarchical linear regression was conducted to examine the moderating effect that the child's gender had on the relationship between parental stress and parent-child relationship satisfaction. In this analysis, child gender was a dummy coded variable with $0=$ female and $1=$ male. Parental stress score was mean-centered to aid in interpretation of the analysis. Using the hierarchical linear regression method, the control variables were entered as the 
first step of the model. In the second step, the predictor and interaction term were inputted into the model. The interaction term was created by multiplying the mean-centered parental stress score by the dummy-coded gender variable for each participant. The change in $R^{2}$ between the two steps was noted.

Results of the first step of the regression model indicated that the demographic control variable did not have an effect on parent-child relationship satisfaction, $\left(F(1,15)=0.90, p=.358, R^{2}=.057\right)$. The $R^{2}$ value indicates that approximately $5.7 \%$ of the variance in parent-child relationship satisfaction scores can be explained by the control variable. The parents age was not a significant predictor in the model.

Results of the second step of the regression model indicated that the demographic variable, parental stress, and parental stress*gender have a significant collective effect on parent-child relationship satisfaction, $(F(4,12)$ $\left.=7.84, p=.002, R^{2}=.723\right)$. The $R^{2}$ value indicates that approximately $72.3 \%$ of the variance in parent-child relationship satisfaction scores can be explained by the control variable and the inclusion of parental stress, gender, and the interaction term in the model. An additional $66.6 \%$ of the variance could be explained by the inclusion of parental stress in the model beyond what is accounted for by the demographic factors alone. Parental stress $(B=-0.24, t$ $=-2.97, p=.012$ ) was a significant predictor in the model, such that with every one-unit increase in parental stress, parental-child relationship satisfaction decreased by 0.24 units. Child gender $(B=6.16, t=2.42, p=$ .032) was a significant predictor in the model, such that the child's gender being male (compared to female) increased parental-child relationship satisfaction by 6.16 units. The interaction term, parental stress*gender $(B=-$ $0.03, t=-0.26, p=.802$ ), was not significant in the model, suggesting that gender was not a moderating factor in the relationship between parental stress and parent-child relationship satisfaction. The null hypothesis $\left(\mathrm{H}_{0} 2\right)$ for research question two could not be rejected. The results for the hierarchical linear regression are presented in Table 5.

Table 5: Results for Regression with the Child's Gender Moderating the Relationship between Parental Stress and Parent-Child Relationship Satisfaction

\begin{tabular}{lcccccc}
\multicolumn{7}{c}{ between Parental Stress and Parent-Child Relationship Satisfaction } \\
\hline Source & $B$ & $S E$ & $\beta$ & $t$ & $p$ & VIF \\
\hline Step 1 & & & & & & \\
Parent age & -1.39 & 1.46 & -0.24 & -0.95 & .358 & 1.00 \\
Step 2 & & & & & & \\
Parent age & -0.12 & 0.92 & -0.02 & -0.13 & .902 & 1.09 \\
Parental stress & -0.24 & 0.08 & -0.63 & -2.97 & .012 & 1.95 \\
Gender & 6.16 & 2.54 & 0.39 & 2.42 & .032 & 1.09 \\
Parental stress*Gender & -0.03 & 0.12 & -0.05 & -0.26 & .802 & 1.82 \\
\hline
\end{tabular}

Note. Step One: $F(1,15)=0.90, p=.358, R^{2}=.057$ 
Step Two: $F(4,12)=7.84, p=.002, R^{2}=.723$

Research Question 3: Does the child's age moderate the relationship between parental stress and the reported satisfaction of the parent-child relationship?

The third analysis examined the moderating effect that the child's age has on the relationship between parental stress and parent-child relationship satisfaction using the scores from the PSI-4-SF and the PCRI. A hierarchical linear regression was conducted to examine the moderating effect that the child's age has on the relationship between parental stress and parent-child relationship satisfaction. Parental stress score and child's age were meancentered to aid in interpretation of the analysis. Using the hierarchical linear regression method, the control variables were entered as the first step of the model. In the second step, the predictor and interaction term were inputted into the model. The interaction term was created by multiplying the meancentered parental stress score by the mean-centered child's age variable for each participant. The change in $R^{2}$ between the two steps was noted.

Results of the first step of the regression model indicated that the demographic control variable did not have an effect on parent-child relationship satisfaction, $\left(F(1,15)=0.90, p=.358, R^{2}=.057\right)$. The $R^{2}$ value indicates that approximately $5.7 \%$ of the variance in parent-child relationship satisfaction scores can be explained by the control variable. The parents age was not a significant predictor in the model.

Results of the second step of the regression model indicated that the demographic variable, parental stress, and parental stress*age have a significant collective effect on parent-child relationship satisfaction, $(F(4,12)$ $\left.=6.25, p=.006, R^{2}=.676\right)$. The $R^{2}$ value indicates that approximately $67.6 \%$ of the variance in parent-child relationship satisfaction scores can be explained by the control variables and the inclusion of parental stress, age, and the interaction term in the model. An additional $61.9 \%$ of the variance could be explained by the inclusion of parental stress in the model beyond what is accounted for by the demographic factors alone. Parental stress $(B=-0.29, t$ $=-4.43, p=.001$ ) was a significant predictor in the model, such that with every one-unit increase in parental stress, parental-child relationship satisfaction decreased by 0.29 units. The interaction term, parental stress*age ( $B=-0.06, t=-1.73, p=.110)$, was not significant in the model, suggesting that child's age was not a moderating factor in the relationship between parental stress and parent-child relationship satisfaction. The null hypothesis $\left(H_{0} 3\right)$ for research question three could not be rejected. The results for the hierarchical linear regression are presented in Table 6. 
Table 6: Results for Regression with the Child's Age Moderating the Relationship between Parental Stress and Parent-Child Relationship Satisfaction

\begin{tabular}{lllllll} 
Source & $B$ & $S E$ & $\beta$ & $t$ & $p$ & VIF \\
Step 1 & & & & & & \\
Parent age & -1.39 & 1.46 & -0.24 & -0.95 & .358 & 1.00 \\
Step 2 & & & & & & \\
Parent age & -0.80 & 1.18 & -0.14 & -0.68 & .511 & 1.52 \\
Parental stress & -0.29 & 0.06 & -0.75 & -4.43 & .001 & 1.05 \\
Child's Age & -0.05 & 0.68 & -0.02 & -0.08 & .940 & 1.69 \\
Parental stress*Age & -0.06 & 0.03 & -0.31 & -1.73 & .110 & 1.20 \\
\hline
\end{tabular}

Note. Step One: $F(1,15)=0.90, p=.358, R^{2}=.057$

Step Two: $F(4,12)=6.25, p=.006, R^{2}=.676$

Based on the results of the Pearson correlation and regression performed for research question 1, the null hypothesis was rejected as there was a statistically significant relationship between parental stress and parentchild relationship satisfaction. Concerning the second research question, the null hypothesis was not rejected as the interaction term, parental stress*gender, was not significant in the model. This suggests that gender was not a moderating factor in the relationship between parental stress and parentchild relationship satisfaction. For the third research question, the null hypothesis was not rejected as the interaction term, parental stress age, was not significant in the model. This suggests that age was not a moderating factor in the relationship between parental stress and parent-child relationship satisfaction.

\section{Conclusion}

This study confirms prior assumptions that shortly following parental separation or divorce, a mother's stress does negatively affect the parent-child relationship (Wallerstein \& Blakeslee, 2003). Following separation or divorce, more than $50 \%$ of mothers have been found to be less responsive to their child's needs as well as being less physically available (Wallerstein et al., 2013). Hence, children who are also experiencing the trauma of their parents' separation often must deal with their feelings by themselves which can impact the parent-child relationship on a permanent basis (Wallerstein, 2005; Wallerstein et al., 2013) as well as have a negative effect on the child's attachment style (Faber \& Whittenborn, 2010). Contrary to previous studies, this study found no influence of the child's gender on the interaction of parental stress and parent-child relationship satisfaction. However, it was found that those mothers that had sons reported higher satisfaction with the parent-child relationship than those mother's that had daughters. This finding was unexpected. Possibly, these males assume a spousal or parental type role with their mothers to help their mothers cope with divorce. This type of 
developmental role is inappropriate but discussed in the literature. Further research into this finding could help researchers to know if this was an aberrant result or a consistent finding. This study showed that the satisfaction of the parent-child relationship diminishes with higher parental stress. Parents, in times of stress, may not notice that their child has a heightened need for attachment type behaviors (Faber \& Whittenborn, 2010), which is of concern. If a parent is over-stressed for a long time and the child's attachment needs are not being met, regardless of age, the parent-child relationship could suffer in the long-term.

Regarding recommendations, we believe that professionals that work with divorced families begin teaching the importance of stress management to maximize the parent-child relationship. Parents who are involved in a separation or divorce need to be warned about the effects of their stress on their child (Sommers-Flanagan \& Barr, 2005). Also, comparing custodial mothers' stress and its effect on father-child relationship to custodial fathers' stress and effects on their parent-child relationships could provide valuable information regarding the differences between mothers and fathers and the development of their children after divorce. Regarding our results that mothers may have closer relationships to their sons after divorce, we believe that this area deserves further study. Parentification of children is not unusual in divorce and male children assuming a more influential role in the family or confidant to the mother may not be atypical, but it is problematic (Yarosh, Chew \& Abowd, 2009). Divorce can be chaotic for families as they seek to find an appropriate balance. Role confusion and distortion can be the result of this chaos and stress in the family.

\section{References:}

1. Abidin, R. R. (2012). Parenting Stress Index, Fourth Edition: Professional Manual. Lutz, Florida: Psychological Assessment Resources.

2. Afifi, T. D., Huber, F. N., \& Ohs, J. (2006). Parents' and adolescents' communication with each other about divorce-related stressors and its impact on their ability to cope positively with the divorce. Journal of Divorce \& Remarriage, 45(1/2), 1-30. doi: 10.1300/J087v45n01_01

3. Beelmann, W. \& Schmidt-Denter, U. (2009). Mother-child interaction following marital separation: A longitudinal observation study. European Psychologist, 14(4), 307-319. doi: 10.1027/10169040.14.4.307

4. Breivik, K. \& Olweus, D. (2006). Adolescent's adjustment in four post-divorce family structures: Single mother, stepfather, joint physical custody and single father families. Journal of Divorce \& Remarriage, 44(3/4), 99-124. doi: 10.1300/J087v44n03_07 
5. Center for Disease Control (2015). National Marriage and Divorce Rate Trends. Retrieved from http://www.cdc.giv/nchs/nvss/marriage_divorce_tables.htm

6. Cohen, O. \& Finzi-Dottan, R. (2005). Parent-child relationships during the divorce process: From attachment theory and intergenerational perspective. Contemporary Family Therapy, 27(1), 81-99. doi: 10.1007/s10591-004-1972-3

7. Eldar-Avidan, D., Haj-Yahia, M. M., \& Greenbaum, C. W. (2008). Money matters: Young adults' perception of the economic consequences of their parents' divorce. Journal of Family Economic Issues, 29, 74-85. doi: 10.1007/s10834-007-9093-4

8. Faber, A. J. \& Wittenborn, A. K. (2010). The role of attachment in children's adjustment to divorce and remarriage. Journal of Family Psychotherapy, 21, 89-104. doi: 10.1080/08975353.2010.483625

9. Gerard, A. B. (1994). Parent- Child Relationship Inventory (PCRI) manual. Los Angeles, CA: Western Psychological Services.

10. Hakvoort, E. M., Bos, H. M. W., Van Balen, F., \& Hermanns, J. M. A. (2012). Spillover between mothers' postdivorce relationships: The mediating role of parenting stress. Personal Relationships, 19(2), 247254. doi: 10.1111/j.1475-6811.2011.01351.x

11. Huurre, T., Junkkari, H., \& Aro, H. (2006). Long-term psychosocial effects of parental divorce: A follow-up study from adolescence to adulthood. European Archives of Psychiatry Clinical Neuroscience, 256(4), 256-263. doi: 10.1007/s00406-006-0641-y

12. Kahl, S. F., Steelman, L. C., Mulkey, L. M., Koch, P. R., Dougan, W. L., \& Catsambis, S. (2007). Revisiting Reuben Hill's theory of familial response to stressors: The mediating role of mental outlook for offspring of divorce. Family and Consumer Sciences Research Journal, 36(1), 5-21. doi: 10.1177/1077727X07303494

13. Kenyon, D. B. \& Koerner, S. S. (2008). Post-divorce maternal disclosure and the father-adolescent relationship: Adolescent emotional autonomy and inter-reactivity as moderators. Journal of Child and Family Studies, 17, 791-808. doi: 10.1007/s10826-0089190-5

14. Koerner, S. S., Kenyon, D. Y. B., \& Rankin, L. A. (2006). Growing up faster? Post-divorce catalysts in the mother-adolescent relationship. Journal of Divorce \& Remarriage, 45(3/4), 25-41. doi: 10.1300/J087v45n03_02

15. Kreider, R. M. \& Ellis, R. (2011). Number, Timing, and Duration of Marriages, and Divorces: 2009. Washington, DC: US Department of Commerce, Economics and Statistics Administration, US Census Bureau. 
16. Kristjansson, A. L., Sigfusdottir, I. D., Allegrante, J. P., \& Helgason, A. R. (2009). Parental divorce and adolescent cigarette smoking and alcohol use: assessing the importance of family conflict. Acta Paediatrica, 98, 537-542. doi: 10.1111/j.1651-2227.2008.01133.x

17. Lamela, D. \& Figueiredo, B. (2011). Post-divorce representations of marital negotiation during marriage predict parenting alliance in newly divorced parents. Sexual and Relationship Therapy, 26(2), 182-190. doi: 10.1080/14681994.2011.563288

18. Lansford, J. E., Malone, P. S., Castellino, D. R., Dodge, K. A., Pettit, G. S., \& Bates, J. E. (2006). Trajectories of internalizing, externalizing, and grades for children who have and have not experienced their parents' divorce or separation. Journal of Family Psychology, 20(2), 292-301. doi: 10.1037/0893-3200.20.2.292

19. Luedemann, M. B., Ehrenberg, M. F., \& Hunter, M. A. (2006). Mothers' discussions with daughters following divorce: Young adults reflect on their adolescent experiences and current mother-daughter relations. Journal of Divorce \& Remarriage, 46(1/2), 29-55. doi: 10.1300/J087v46n01_03

20. Sommers-Flanagan, J. \& Barr, L. (2005). Three constructive interventions for divorced, divorcing, or never-married parents. The Family Journal: Counseling and Therapy for Couples and Families, 13(4), 482-486. doi: 10.1177/1066480705278725

21. Sutherland, K. E., Altenhofen, S., \& Biringen, Z. (2012). Emotional availability during mother-child interactions in divorcing and intact married families. Journal of Divorce \& Remarriage, 53, 126-141. doi: 10.1080/10502556.2011.651974

22. Taylor, D. D., Purswell, K., Lindo, N., Jayne, K., \& Fernando, D. (2011). The impact of child parent relationship therapy on child behavior and parent-child relationships: An examination of parental divorce. International Journal of Play Therapy, 20(3), 124-137. doi: 10.1037/a0024469

23. Wallerstein, J. S. (2005). Growing up in the divorced family. Clinical Social Work Journal, 33(4), 401-418. doi: 10.1007/s10615-005-7034$\mathrm{y}$

24. Wallerstein, J. S. \& Blakeslee, S. (2003). What about the kids? Raising your children before, during, and after divorce. New York: Hyperion.

25. Wallerstein, J., Lewis, J., \& Rosenthal, S. P. (2013). Mothers and their children after divorce: Report from a 25-year longitudinal study. Psychoanalytic Psychology, 30(2), 167-187. doi: 10.1037/a0032511

26. Yarosh, S., Chew, Y. C. D., \& Abowd, G. D. (2009). Supporting parent-child communication in divorced families. International 
Journal of Human-Computer Studies, 67, 192-203. doi: 10.1016/j.ijhcs.2008.09.005. 